\title{
7. ANTÍGONA E O ENSINO JURÍDICO: CONVITE À EDUCAÇÃO REFLEXIVA, CRÍTICA, EMANCIPADORA E TRANSFORMADORA
}

\section{ANTIGONE AND LAW EDUCATION: INVITATION TO EDUCATION REFLEXIVE, CRITICAL, EMANCIPATORY AND TRANSFORMING}

\author{
Alexandre Torres Petry ${ }^{1}$
}

\begin{abstract}
RESUMO
O presente artigo analisa a obra Antígona a partir do prisma do ensino jurídico. Busca-se demonstrar que as concepções trazidas por Antígona, geralmente ligadas ao surgimento do direito natural, contribuem muito sobre a reflexão do atual estágio do ensino jurídico, o qual não responde aos anseios sociais e necessita de uma mudança paradigmática. Antígona representa uma luta contra a injustiça. O ensino jurídico também deve ser pautado na busca pela erradicação das injustiças. Para que haja essa mudança, necessariamente, o ensino jurídico deve ser pautado numa educação reflexiva, crítica, emancipadora e que leve a transformação social. Ao final, conclui-se que somente a educação que siga estes critérios é que poderá levar a uma verdadeira e efetiva transformação social a fim de combater as desiguales que assolam a sociedade.
\end{abstract}

PALAVRAS-CHAVE: Antígona. Ensino Jurídico. Educação. Transformação Social.

\begin{abstract}
This article analyzes Antigone from the prism of law (legal) education. Aims to demonstrate that the concepts brought by Antigone, often linked to the emergence of natural law, contribute much reflection on the current state of law education, which does not respond to social demands and needs a paradigm change. Antigone is a fight against injustice. The law education should also be guided by the search for the eradication of injustice. For this change to occur, necessarily, the law education must be based on a reflective education, critical, emancipatory and leads to social transformation. Finally, it is concluded that only education that follow these criteria is that could lead to a true and effective social change to combat social inequalities that harm society.
\end{abstract}

KEYWORDS: Antigone. Law (Legal) Education. Education. Feminism. Social Transformation.

\section{INTRODUÇÃO}

A obra de Sófocles, Antígona, já possui mais de 2400 anos, sendo que remete à Grécia Clássica, período em que, segundo José Reinaldo de Lima Lopes ${ }^{2}$, não existia uma classe de

\footnotetext{
${ }^{1}$ Doutorando em Educação na UFRGS. Mestre em Direito pela PUCRS. Especialista em Direito e Economia pela UFRGS. Especialista em Direito do Consumidor e Direitos Fundamentais pela UFRGS. Graduado em Direito pela UFRGS. Membro da Comissão de Ensino Jurídico da OAB/RS. Professor e Advogado. Endereço eletrônico: alexandre@petry.adv.br.

${ }^{2}$ LOPES, José Reinaldo de Lima. O direito na história: lições introdutórias. 5. ed. São Paulo: Atlas, 2014. p. 20.
} 
juristas, um treinamento jurídico, escolas de direito e sequer ensino de direito com técnicas específicas. O que estava presente neste período eram as escolas de retórica, dialética e filosofia.

Então, nesse contexto, seria possível estabelecer alguma conexão entre Antígona e o ensino jurídico? Como vincular a atualidade da educação jurídica com uma obra tão distante da nossa realidade? O que essa obra nos ensina e acrescenta? Estas são indagações que se pretende responder ao longo do presente artigo, buscando-se demonstrar que a obra Antígona tem muito a contribuir, pois inspira uma mudança de postura do ensino jurídico, que precisa adotar uma nova roupagem

Modernamente, o direito nunca esteve tão presente e, ao mesmo, tão longe nos embates travados na sociedade. Há uma discussão constante sobre direitos. Postulam-se direitos com frequência e cada vez em maior escala (expansão e efetivação dos direitos). Acredita-se na busca de direitos para melhorar a sociedade. Concomitantemente, o direito como ciência parece distante das pessoas, que desconfiam, questionam e se sentem afastadas de um sistema jurídico que muitas vezes serve para manter uma ordem visivelmente injusta. O direito passa a ser questionado, desacreditado e mesmo contestado.

Essas contradições e reflexões precisam ser afloradas no ensino jurídico. Antígona demonstra a luta contra o injusto, contra a tirania. Antígona reflete a crítica ao sistema legal injusto. $\mathrm{O}$ ensino jurídico, da mesma forma, tem que enfrentar as injustiças, adotando postura reflexiva e crítica que crie as condições de emancipação dos estudantes de direito e redunde, necessariamente, em transformação social.

\section{ANTÍGONA E O DEBATE JURÍDICO}

Antígona é uma das mais antigas dentre as tragédias conservadas de Sófocles, provavelmente escrita entre os anos de 421 a 422 a.C. Trata-se da história de dois irmãos que, após uma batalha sangrenta, entrematam-se na luta pelo poder. Creonte é que acaba assumindo o poder e o seu primeiro ato é o de proibir o sepultamento de um dos irmãos (considerado o traidor: Polinice) enquanto ordena funerais de heróis ao outro irmão (Etéocles). Entretanto, Antígona desobedece a ordem e decide prestar honras fúnebres ao irmão Polinice, sustentando para tanto ou seu direito individual (outorgado pelos deuses), o qual estaria em contradição ao 
direito positivo estabelecido. As consequências deste ato são trágicas, pois Antígona é levada a morte por sepultar o seu próprio irmão abandonado. ${ }^{3}$

Desta tragédia grega, considerando a riqueza da obra, várias são as possibilidades de abordagem e reflexão, como, por exemplo: a questão religiosa, a moral, a política, a jurídica, a literária e mesmo a educacional. Aqui importa fazer a conexão entre Direito e Educação.

$\mathrm{Na}$ área jurídica, a peça Antígona ficou marcada e conhecida por ser o primeiro "desenho" do chamado Direito Natural, o qual suscitou muitos debates ao longo da história e possui extrema relevância até a atualidade. Neste sentido, cita-se Adhemar Ferreira Maciel' ${ }^{4}$ :

Mas, sem dúvidas, na Antígona vamos encontrar um primeiro escorço do denominado "direito natural", que tanta divergência ainda traz entre os juspositivistas e jusnaturalistas. A revolta de Antígona, por sua vez, assinala o "direito de resistência", "a desobediência civil", que hoje figura até nos catálogos dos direitos fundamentais de alguns povos, e foi a chama que alimentou teóricos da limitação do poder, como John Locke e ativistas como John Brown e Henry David Thoreau.

Ao invocar leis não escritas, Antígona, na verdade, afirmava que acima das leis do Estado (ordem legal constituída), ou seja, as leis escritas, existem leis universais que deveriam sempre prevalecer sobre as leis positivadas, já que calcadas na natureza humana. Costuma-se apontar essa revolta de Antígona como sendo o germe do direito natural. ${ }^{5}$ Também se verifica uma oposição entre valores individuais frente aos parâmetros normativos postos à coletividade. ${ }^{6}$

É tamanha a importância da peça de Sófocles que Alexandre de Moraes sustenta que a ideia defendida por Antígona deve ser considerada como fonte histórica da evolução dos direitos do homem. ${ }^{7}$

São muitas as antinomias e embates travados na peça, sobressaindo-se a questão do direito natural do homem, o qual teria o direito inerente da liberdade independentemente de atos normativos. Portanto, de acordo com Bruno Boaventura, ocorre nessa tragédia a individualização

\footnotetext{
3 De acordo com GUIMARÃES, Cristiane Santana. Antígona, o exercício do direito natural. Revista da Procuradoria Geral do Estado da Bahia. Salvador, v. 31, p. 11-16, jul./dez., 2005. p. 12.

4 MACIEL, Adhemar Ferreira. Um pouco de Antígona e de direito natural. Revista de Informação Legislativa, Brasília, n.132, p.37-38, 1996. p. 37.

${ }^{5}$ De acordo com CALHAU, Lélio Braga. O devido processo legal no processo penal: Da Antígona ao garantismo. $O$ Direito em Movimento: Revista do Instituto Capixaba de Estudos. Vitoria, v.1, p.125-142. 2000. p. 127.

${ }^{6}$ Conforme MUNIZ, Veyzon Campos. Superando Antígona. A distinção entre direito público e direito privado Limites, enfraquecimento e consequências operacionais a partir de uma análise hermenêutica. Revista do Instituto de Hermenêutica Jurídica, Belo Horizonte, n.14, p.169-183, jul./dez. 2013. p. 170.

${ }^{7}$ MORAES, Alexandre de. Direitos humanos fundamentais. 3. ed. São Paulo: Atlas, 2000. p. 25.
} 
do homem à norma superior, construindo-se assim a subjetividade do direito. Sobre a importância de Antígona, assim destaca o autor ${ }^{8}$ :

A primeira importância da peça ao direito é a inicialização, e consequente universalização, da ideia de antinomia jurídica. Neste aspecto ganha importância histórica, pois podemos enxergar o embrião dos critérios solucionadores (hierárquico e cronológico) das antinomias. Existe a construção de patamares normativos, o do divino e do homem, e, o tempo como critério, mas precisamente a atemporalidade da Lei-divina como forma de solucionamento do conflito normativo.

A peça Antígona, como refere T. Lisieux Maia, permite várias conclusões, principalmente, que toda ação humana é suscetível de erro, bem como que não existem regras imutáveis, aliás, considerações estas confirmadas pela experiência histórica. Porém, outra consideração referida pela autora que merece destaque sobre Antígona é a função educadora, assim destacada ${ }^{9}$ :

A tragédia grega está sempre a nos ensinar, por ter nascido com a função precípua de educar o público, apontando para os vários pontos de vista do conflito, permitindo, a partir dos argumentos apresentados, a formação de opiniões, por parte dos assistentes.

Sem dúvidas, do ponto de vista jurídico, a principal contribuição de Antígona é introduzir a discussão do direito natural, uma vez que o jusnaturalismo foi fundamental em diversos momentos históricos. Não se nega essa importância. Entretanto, outra contribuição essencial está ligada ao ensino jurídico, essa pouco explorada. Isso porque a tragédia grega, que nasceu justamente para educar, apontando vários prismas de um mesmo conflito, traz na plateia a reflexão, o embate, a dúvida, a comoção e o desenvolvimento de opiniões diversas.

Essa vertente educacional é de extrema importância, pois o ensino jurídico ainda é muito calcado no direito posto, no direito escrito, estatal e, portanto, numa lógica de manutenção do status já estabelecido, ainda que este seja fonte de desigualdades. Não se está aqui postulando a docência do direito natural. Pelo contrário, o que se pretende é destacar justamente a missão educacional de Antígona, capaz de gerar profundo apego da plateia (dos educandos) a qual se envolve de tal maneira que reflete sobre o tema e não consegue ficar indiferente.

\footnotetext{
BOAVENTURA, Bruno José Ricci. Antígona: a mãe da individualização do direito. Direito e Democracia: Revista de Ciências Jurídicas, Canoas, v.9, n.1, p. 120-129, jan./jun. 2008. p. 128.

9 MAIA, T. Lisieux. Antígona: o trágico da ação e o aprendizado de si. Pensar: Revista do Curso de Direito da Universidade de Fortaleza, Fortaleza, v. 13, n. 1, p. 148-157, jan./jun. 2008. p. 150.
} 
É justamente isso que se espera dos discentes na área do direito: reflexão, crítica, emancipação e transformação. Entretanto, o atual estágio ensino do jurídico não tem conseguindo cumprir essa missão, sendo várias as causas para a crise do ensino jurídico, ainda muito ligado a dogmas que mantém paradigmas já ultrapassados e inadequados aos anseios de uma moderna e complexa sociedade.

Cativar os alunos a resolverem problemas ou dilemas como viveu Antígona é de extrema importância, pois coloca os discentes em situação de grande dificuldade e exige respostas elaboradas e devidamente fundamentadas, as quais vão revelar muito sobre os próprios sujeitos pensantes. Reflexões profundas como essas exigem uma postura crítica capaz de gerar conhecimento e, a partir de então, emancipam o aluno, que se torna habilitado a atuar e transformar a sociedade em que vive.

A peça Antígona é instigante e intrigante, até mesmo apaixonante. $\mathrm{O}$ ensino jurídico também precisa ter estas qualidades a fim de potencializar nos alunos a reflexão, a crítica, promover a emancipação e, finalmente, criar os pressupostos para a transformação social, justamente o que se espera de um jurista moderno comprometido com o Direito.

\section{O ENSINO JURÍDICO COMO UMA PRÁTICA REFLEXIVA}

Historicamente, os cursos jurídicos se destacam por serem destinados à formação das elites brasileiras, sendo que desde 1827, data da fundação dos primeiros cursos jurídicos no Brasil, substancialmente, pouca coisa mudou. Nessa linha, as aulas dos cursos de direito não costumam (no geral) permitir uma prática reflexiva, já que o ensino se dá através da "educação bancária" ${ }^{10}$, acreditando-se ainda na "transmissão de conhecimento", a qual ocorreria pela análise da legislação e jurisprudência sobre determinado ramo do Direito. A respeito da inadequação do ensino jurídico atual, que ainda está calcado na descontextualização, no dogmatismo e na unidisciplinariedade, transcreve-se as palavras de Juliana Ferrari de Oliveira ${ }^{11}$ :

\footnotetext{
${ }^{10}$ Educação Bancária, segundo Paulo Freire, reflete o apego aos valores tradicionais da educação, em que o aluno tem pouca importância no processo educativo, já que este apenas receberia o conhecimento transmitido pelo professor, educação esta muito combatida pelo próprio Paulo Freire, já que não refletiria a verdadeira educação baseada no diálogo e inteiração entre educador e educando. Essa linha de pensamento aparece em toda a obra de Paulo Freire, destacando-se em especial seu último livro "Pedagogia da Autonomia". FREIRE, Paulo. Pedagogia da autonomia: saberes necessários à prática educativa. São Paulo: Paz e Terra, 2011.

${ }^{11}$ OLIVEIRA, Juliana Ferreira de. Ensino jurídico: história que explica a prática docente. In: MIGUEL, Paula Castello; OLIVEIRA, Juliana Ferreira de (Orgs.). Ensino jurídico: experiências inovadoras. Rio de Janeiro: Lumen Juris, 2010. p. 4.
} 
Neste sentido, o discurso da sala de aula é dissociado da realidade e assimilado como se fosse o único possível. Não há espaço, nem incentivo para a crítica e para a reflexão. O professor, especialista de sua disciplina, é responsável por transmitir seu conhecimento ao aluno, que deve absorvê-lo automaticamente.

Esse ensino jurídico predominante ainda é, infelizmente, um processo de memorização com conteúdos que se repetem de forma idêntica em todos os semestres, estruturados numa prática meramente legalista, ou seja, conhecimento das normas, a qual não capacita os novos operadores a enfrentarem verdadeiros problemas sociais, constituindo-se, assim, como refere Fabiano Lepre Marques "numa verdadeira farsa na qual o professor finge que ensina e os alunos representam que aprendem". 12

Esse apego ao puro conhecimento do sistema legal não tem mais sentido, já que totalmente desligado da realidade social, servindo muito mais para manter um sistema sabidamente desigual do que promover as reais mudanças esperadas pelos operadores da justiça. Nessa linha, cita-se João Ribeiro Júnior ${ }^{13}$ :

Até hoje vemos que tem mais valor conhecer as leis sancionadas pelo poder público e pela jurisprudência dos tribunais - que servem para regulamentar e legitimar os interesses de toda uma tradição jurídica -, do que conhecer a realidade socioeconômica em que se vive. E com isso não se conhece (ou não se quer conhecer) a emergência e a existência de um "novo" Direito fora das normas positivas, que se assenta em pressupostos que se baseiam nas condições históricas e nas práticas cotidianas emergentes. $\mathrm{O}$ conhecimento reproduzido no ensino do Direito sempre foi desconectado da realidade social, na qual vai ser atualizado.

Ora, o ensino jurídico precisa estar conectado com a realidade social, jamais podendo ser medido, ou avaliado, pelo simples resultados nas avaliações em que são cobradas as "verdades" do professor sem que se exija do aluno uma verdadeira reflexão sobre a temática abordada.

Porém, a efetiva reflexão dos alunos apenas ocorrerá mediante mudança de postura dos docentes, que precisam abandonar a ultrapassada educação bancária e promover a ecologia dos saberes que, segundo Boaventura de Sousa Santos, significa o "conjunto de práticas que

\footnotetext{
12 MARQUES, Fabiano Lepre. Ensino jurídico: o embate entre a formação docente e o pacto de mediocridade. Revista de Direito Educacional, São Paulo, n. 3, p. 189-207, jan./jun. 2011. p. 196.

13 RIBEIRO JÚNIOR, João. A formação pedagógica do professor de Direito: conteúdos e alternativas metodológicas para a qualidade do ensino do Direito. Campinas: Papirus, 2001. p. 17.
} 
promovam uma convivência activa de saberes no pressuposto que todos eles, incluindo o saber científico, se podem enriquecer nesse diálogo". ${ }^{4}$

A partir dessa nova postura de adoção da ecologia dos saberes, possibilitar-se-á verdadeiro diálogo entre professores e alunos, já que estes últimos terão suas experiências e saberes considerados no processo educativo. Sobre a ecologia dos saberes no ensino jurídico e a necessidade de interferência positiva na sociedade, cita-se ainda Anna Luiza De Castro Gianasi ${ }^{15}$ :

A importância dessa perspectiva em um curso de Direito é latente, porque só tem sentido se cogitar a educação jurídica se, ao fim e ao cabo, as práticas educativas sugeridas forem adequadas e suficientes para promover o incremento gradativo da responsabilidade do aluno e do professor pela efetiva melhoria das condições de vida da sociedade na qual estão inseridos.

Portanto, o ensino jurídico, primordialmente, deve promover no aluno a reflexão, pois apenas desse modo é que estarão presentes as condições para uma verdadeira educação, a qual ocorrerá pelo diálogo, pela inteiração entre professor e aluno. E essa reflexão deve levar a crítica, ou melhor, espera-se do aluno de direito uma reflexão crítica e uma postura de contestação.

O pressuposto estabelecido por Paulo Freire ${ }^{16}$ que "ensinar exige reflexão crítica sobre a prática" faz todo o sentido para o ensino jurídico que se tem como o ideal, uma vez que o professor de direito deve possuir uma robusta formação geral, com ênfase humanística e axiológica, demonstrando este docente postura reflexiva e visão crítica, seja sobre a matéria que leciona seja sobre o seu próprio ensinar. ${ }^{17}$

Logo, necessariamente, o ensino jurídico deve gerar no aluno uma postura crítica, uma posição de indignação com as injustiças e desigualdades latentes na sociedade.

\section{CRÍTICA E PEDAGOGIA JURÍDICA}

\footnotetext{
${ }^{14}$ SANTOS, Boaventura de Sousa. A universidade no século XXI: para uma reforma democrática e emancipatória da universidade. São Paulo: Cortez, 2004. p. 77.

${ }^{15}$ GIANASI, Anna Luiza De Castro. A extensão na sala de aula: reflexões sobre a aplicabilidade de metodologia d problematização como instrumento de promoção da cidadania. In: XIMENES, Julia Maurmann; SILVA, Larissa Tefen (Orgs). Ensinar direito o Direito. São Paulo: Saraiva, 2015. p.162

${ }^{16}$ FREIRE, Paulo. Pedagogia da autonomia: saberes necessários à prática educativa. São Paulo: Paz e Terra, 2011. p. 39.

${ }^{17}$ De acordo com MOTA, Sergio Ricardo Ferreira. Metodologia do ensino crítico do Direito Tributário no Brasil: uma proposta para a superação da crise do ensino jurídico. Revista de Direito Educacional, São Paulo, n. 4, p. 337360, jul./dez. 2011. p. 348.
} 
Desde a Constituição Federal de 1988, sistematicamente estão sendo criadas normas com o escopo de promover mudanças na estrutura dos cursos de Direito, porém, os referidos dispositivos encontram resistência por parte dos destinatários que justamente deveriam promover as mudanças, ou seja, os próprios responsáveis pelos cursos jurídicos. Essa realidade demonstra que as partes envolvidas nesse processo de crise preferem ficar numa situação de conforto, nutrindo o status já vigente ao invés de romper com os paradigmas. ${ }^{18}$

A maioria dos cursos de Direito estão ligados a um modelo ultrapassado e descomprometido com a histórica, possuindo uma visão de manutenção do sistema vigente, sendo alheios às críticas que recebem. Aliás, os cursos jurídicos costumam ser os mais tradicionais e resistentes focos da universidade no que tange às mudanças e transformações. Essa linha presa ao velho modelo ainda privilegia o objeto e o modelo discursivo centrado no professor em detrimento do diálogo e interação com o aluno. Permanece a crença que bastam professores, códigos e modelos para expor o conhecimento jurídico, deixando-se a pesquisa e a extensão para um segundo plano sem qualquer valorização. Nesse contexto, dificilmente se desenvolverá no aluno uma visão crítica do fenômeno jurídico, ideal que deveria ser buscado por todos os cursos jurídicos. ${ }^{19}$

Ser crítico, ter um pensamento crítico e participar ativamente das aulas nos cursos jurídicos é extremamente importante para um profícuo aprendizado. Apenas assistir aulas e reproduzir o já dito não é propiciar conhecimento, mas tão somente o exercício de memória, o qual não tem sentido na sociedade atual. As palavras de Raquel Sanchez e Fernanda Soares bem sintetizam isso ${ }^{20}$ :

O mundo contemporâneo exige profissionais cada vez mais críticos e participativos, com percepção sócio-econômica do ambiente em que vivem, profissionais que busquem melhorar a sociedade. Assim, para que o profissional formado pela educação jurídica atinja essas características, é preciso seja estimulado a exercitar um olhar humanista, além de deter o conhecimento técnico e prático para construir uma sociedade livre, justa e solidária, como é almejado por nossa Carta Magna.

\footnotetext{
18 Conforme KRETSCHMANN, Ângela; OHLWEILER, Leonel Pires. Desencantamento do ensino jurídico: um paralelo com "O Admirável Mundo Novo", de Huxley. Revista Jurídica do Cesuca. v.4, n. 6, jul/2014, p. 123, disponível em: http://ojs.cesuca.edu.br/index.php/dialogosdodireito/issue/view/34\#.VFT4aodIgmU.

${ }^{19}$ Segundo SANTOS, André Leonardo Copetti; MORAIS, José Luis Bolzan de. O ensino jurídico e a formação do Bacharel em Direito: diretrizes político-pedagógicas do curso de Direito da UNISINOS. Porto Alegre: Livraria do Advogado, 2007. p. 61.

${ }^{20}$ SANCHES, Raquel Cristina Ferraroni; SOARES, Fernanda Heloisa Macedo. Construção da identidade docente do professor de direito. São Paulo: Letras Jurídicas, 2014. p. 120.
} 
Atualmente, é fundamental um olhar aguçado acerca da realidade social. Mais do que isso, impõe-se uma inteiração entre os ensinamentos de sala de aula e o mundo exterior. Para tanto, o pensamento crítico precisa estar sempre presente, pois essa postura de inquietação, inteiração, dúvida e ressignificação produz pontes entre os conhecimentos já produzidos pelo aluno com as novidades propiciadas pelo ensino jurídico, promovendo-se verdadeiro processo de diálogo, o qual é fundamental na educação.

Logo, o ensino jurídico não pode ser concebido sem uma postura crítica. Nessa linha, transcrevem-se os ensinamentos de Regina Célia Pedroso ${ }^{21}$ :

O pensamento crítico, por sua vez, importante dentro da análise subjetiva, traz o posicionamento do autor frente ao fato analisado, podendo este trazer novas interpretações e questionamentos, permitindo-nos uma melhor compreensão do mundo em que vivemos. A importância da visão crítica está acima da religião, da política ou mesmo dos pré-conceitos de que somos portadores. Observar a realidade social a partir do posicionamento isento e científico é importante para que possamos toar consciência e tomar partido.

Porém, a qualidade do ensino jurídico tem piorado no Brasil, principalmente nas últimas duas décadas. Uma das causas é a falta de investimento nos professores, além do que métodos mais eficientes de aprendizagem continuam sendo ignorados. Não bastasse isso, muitas vezes os alunos são tratados como verdadeiros consumidores, os quais são agraciados com "perfumarias e mimos". A soma de tudo isso resulta em profissionais despreparados e que maciçamente são reprovados nos exames da $\mathrm{OAB} .^{22}$

Desta forma, a consciência crítica é importante frente à complexidade em que vivemos, sendo que quanto mais visão crítica for adotada, mais aptidão terão tanto o docente como o discente frente ao mundo que estão inseridos, diminuindo-se consideravelmente as chances de erro para as tomadas de decisões. ${ }^{23}$

\footnotetext{
${ }^{21}$ PEDROSO, Regina Célia. Ciências sociais e direito: pensar o mundo a partir da reflexão crítica. In: PINTO, Daniella Basso Batista; CINTIA; Rodrigo Suzuki (Orgs). Direito e educação: reflexões críticas para uma perspectiva interdisciplinar. São Paulo: Saraiva, 2013. p. 146.

22 De acordo com LIMA, Francisco Gérson Marques de. O professor no direito brasileiro: orientações fundamentais de direito do trabalho. Rio de Janeiro: Forense, 2008. p. 13.

${ }^{23}$ Conforme PEDROSO, Regina Célia. Ciências sociais e direito: pensar o mundo a partir da reflexão crítica. In: PINTO, Daniella Basso Batista; CINTIA; Rodrigo Suzuki (Orgs). Direito e educação: reflexões críticas para uma perspectiva interdisciplinar. São Paulo: Saraiva, 2013. p. 148.
} 
É fundamental que o ensino jurídico seja, conforme expõe Julio Siqueira ${ }^{24}$, “colaborativo, cooperativo, participativo, que tanto os alunos, quanto os professores e a instituição atuem em conjunto e se conscientizem de que são agentes de um mesmo processo de ensino aprendizagem".

O ensino jurídico deve promover um constante saber crítico, conforme expõe Alexandra Silva $\mathrm{Scoz}^{25}$ :

Uma pedagogia que incentive a ampla liberdade no processo de ensinoaprendizagem jurídico de graduação parece coadunar com os anseios contemporâneos que fomentam o desejo pelo saber, um saber crítico, inusitado, reflexivo, rebelde e não domesticável pela prática automática de reprodução de um objeto estéril, de certezas emprestadas, que proíbe pensar além do disposto em suas normas, numa simbólica forma de controle e totalitarismo a fantasiar a realidade.

Essa postura crítica deve ser uma constante, pois, como refere Bárbara Silva Costa, necessariamente o ensino jurídico deve ser "mais crítico e reflexivo, a fim de formar, e não (de)formar, profissionais capazes de agir diante das complexidades do século XXI" ${ }^{26}$ A visão crítica é pois requisito fundamental de um verdadeiro ensino jurídico que se preocupe com a busca e promoção da justiça.

\section{ENSINO JURÍDICO COMO FORMA DE EMANCIPAÇÃO}

Deve-se sempre frisar que o direito à educação possui fundamentalidade, uma vez que a educação é um aspecto do direito à vida, já que pela educação é que se possibilita uma vida digna, ao mesmo tempo em que também possui um aspecto de direto à liberdade, considerando que pode assegurar ao cidadão as decisões e condução do seu destino na sociedade. ${ }^{27}$

Logo, educação deveria ser sempre emancipadora, mas, na prática, nem sempre isso ocorre, principalmente quando a educação esquece ou esconde seus verdadeiros valores. Assumindo a educação um papel reflexivo e crítico, certamente, possibilitará as condições de

\footnotetext{
${ }^{24}$ SIQUEIRA, Julio Pinheiro Faro Homem de. Ensino jurídico: em busca do habitus de transformação. Revista de Direito Educacional, São Paulo, n. 3, p. 217-260, jan./jun. 2011. p. 257

${ }^{25} \mathrm{SCOZ}$, Alexandra Silva. Ensino jurídico de graduação brasileiro: ensaio sobre a produção de direito na pósmodernidade. Rio de Janeiro: Lumen Juris, 2012. p. 140.

${ }^{26}$ COSTA, Bárbara Silva. (Re)pensando o direito diante de um mundo global: uma reflexão sobre os desafios do ensino jurídico no século XXI. In: CERQUEIRA, Angélica Carlini; ALMEIDA FILHO, José Carlos de Araújo (Orgs). 180 anos de ensino jurídico no Brasil. Campinas: Millennium, 2007. p. 376.

${ }^{27}$ De acordo com ANDRADE, Cássio Cavalcante. Direito educacional: interpretação do direito educacional à educação. Belo Horizonte: Fórum, 2010. p. 201.
} 
emancipação por parte do aluno, já que poderá se tornar um agente capaz de analisar o mundo que o cerca de forma crítica.

Sendo emancipadora, a educação deve ser exercida a fim de tornar a sociedade mais harmônica, sustentável e justa, o que se dará pela adoção de uma educação humanista com foco na dignidade da pessoa humana e também promoção dos direitos humanos.

Nesse diapasão, o ensino jurídico também deve possibilitar as condições de emancipação dos futuros juristas. Tanto professor como aluno devem buscar a libertação dos ultrapassados dogmas do Direito, como bem refere Sérgio Rodrigo Martínez ${ }^{28}$ :

Libertar-se é antes de tudo aprender a respeitar a liberdade dos outros, inconscientes ou não da dialética libertária quer entre opressores e oprimidos, quer entre educadores "bancários" ou não, e, agir, no máximo, em forma de esclarecimento com vistas à produção, aos poucos, de reciclagens individuais em todo o elenco do processo de ensino e aprendizagem, com base nos novos paradigmas existentes para o ensino jurídico.

Segundo Paulo Freire, todo educador precisa ser consciente que "ensinar exige compreender que a educação é uma forma de intervenção no mundo". ${ }^{29}$ Ora, sem dúvidas educação é libertadora e precisa estimular o aprendizado global, que é aquele que se refere ao uso da ação e reflexão para acabar com a desumanização do mundo contemporâneo. As abordagens educacionais precisam ser libertadoras e, para atingir essa perspectiva, três são os seus pressupostos mínimos: respeito pelo outro(a), o amor e a esperança. ${ }^{30}$

Portanto, o ensino jurídico precisa considerar também outros importantes valores na educação, como amor e esperança. Essa vertente mais humanizada ampliará o leque de saberes, dando aos educadores e educando possibilidade de compreensão e interferência no mundo. Nessa perspectiva de mudança, torna-se e importante referir as palavras de Giovani de Paula ${ }^{31}$ :

Assim, no ensino do direito o papel do professor diante deste contexto deve ser não apenas o de ensinar, mas sim o de ampliar as possibilidades de saberes, demonstrando a sua importância e pertinência social, apontando caminhos que despertem os alunos para uma consciência crítica, de forma que percebam suas

\footnotetext{
${ }^{28}$ MARTínEZ, Sérgio Rodrigo. Pedagogia jurídica. Curitiba: Juruá, 2012. p. 42.

${ }^{29}$ FREIRE, Paulo. Pedagogia da autonomia: saberes necessários à prática educativa. São Paulo: Paz e Terra, 2011. p. 96.

${ }^{30}$ GERHARDT, Heinz-Peter. Educação libertadora e globalização. In: FREIRE, Ana Maria Araújo (Org.). A pedagogia da libertação em Paulo Freire. São Paulo: Editora UNESP, 2001, p. 114.

31 PAULA, Giovani de. Alternativas pedagógicas para o ensino jurídico. In: COLAÇO, Thais Luzia (org.). Aprendendo a ensinar direito O DIREITO. Florianópolis: OAB/SC Editora, 2006, p. 219.
} 
contradições e busquem a integração entre a informação, o conhecimento e o contexto social, criando condições de mudanças e de compreensão do mundo a nossa volta.

A reflexão crítica permite a emancipação, sendo que o aluno emancipado adquire as verdadeiras condições de atuação no mundo e, a partir de então, de promover efetiva e benéfica transformação social, quando o ensino jurídico terá trilhado todo o caminho que dele legitimamente se espera: melhorar a sociedade.

\section{OBJETIVO DO ENSINO JURÍDICO: TRANSFORMAÇÃO SOCIAL}

O papel da educação jamais pode ser o de manutenção da ordem social já estabelecida, pois se assim for estaremos diante de uma situação de imobilidade, ou seja, de reprodução da realidade, o que se agrava no Brasil, país com profundas desigualdades sociais. Logo, a educação precisa abrir horizontes, possibilitando ao educando a transformação no meio social em que vive.

A educação é transformadora porque permite aos cidadãos descobrir e reconhecer os seus direitos básicos, entre eles os direitos fundamentais, como a dignidade da pessoa humana, o que se concretiza numa sociedade democrática. ${ }^{32}$

Logo, a educação é um guia condutor de uma sociedade, pois conforme destaca Daniella Basso Batista Pinto, “a educação é estratégia certeira do desenvolvimento de uma nação e de seu povo, pois ela cria uma consciência coletiva e de respeito à dignidade da pessoa humana". ${ }^{33}$

Assume a educação um papel primordial e privilegiado para a construção de uma ética de respeito e uma formação humanista com foco na dignidade da pessoa humana, pois é através da educação que se consegue desconstruir mitos e preconceitos, insculpindo-se nas pessoas os valores realmente essenciais para a formatação de uma sociedade mais justa e harmônica. ${ }^{34}$

Se a educação tem a capacidade de transformar, de mudar a sociedade, precisa ser na direção da promoção dos direitos, principalmente os direitos humanos. Esse potencial de transformação social, sem dúvidas, é ainda mais potencializado no caso do ensino jurídico, uma

\footnotetext{
${ }^{32}$ Conforme ABIKAIR FILHO, Jorge. Democracia e educação para a cidadania, como uma forma de inclusão social. Revista de Direito Educacional, São Paulo, n. 5, p. 87-104, jan./jun. 2012. p. 103.

${ }^{33}$ PAICENTIN, Antonio Isidoro. O direito à educação na Constituição Democrática de 1988. In: PINTO, Daniella Basso Batista; CINTRA, Rodrigo Suzuki (Orgs.). Direito e educação: reflexões críticas para uma perspectiva interdisciplinar. São Paulo: Saraiva, 2013.p. 67.

34 Segundo OLIVEIRA, Rosa Maria R. de. Gênero, diversidade sexual e direitos humanos. In: RIFIOTIS, Theophilos; RODRIGUES, Tiago Hyra (Orgs.). Educação em direitos humanos: discursos críticos e temas contemporâneos. Florianópolis: Ed. da UFSC, 2008. p. 222.
} 
vez que a formação de juristas e operadores do direito é essencial para uma sociedade em que se busque efetiva cidadania e justiça social.

Duncan Kennedy defende que o ensino de direito é, inclusive, uma forma de ação política, em que o docente precisa apresentar aos estudantes o mundo real e suas ideologias, sendo que o discente precisa abandonar o mundo idealizado da sala de aula e conhecer a realidade que o cerca ${ }^{35}$ :

La ideia era sacar los estudiantes del contexto idealizado de la facultad de derecho, donde no tenían posibilidad alguna de entender cómo son en realidad las cosas, y exponerlos a la vida en estado crudo. Supuestamente eso les haría ver que corrían peligro de ser absorbidos por una estructura conservadora y profundamente inmoral de prestación de servicios jurídicos, predispuesta a favor de los ricos y en contra de los pobres, y disimulada con una ética falsa.

É através da formação de alunos reflexivos, críticos e emancipados que será possível uma verdadeira transformação social, pois estes futuros juristas precisam ter conhecimento da sociedade em que vivem e buscar interferir na mesma de forma a reduzir as desigualdades existentes. Nessa linha, torna-se importante destacar as palavras de Horácio Wanderlei Rodrigues $^{36}$ :

O ensino do Direito deve, para mudar essa realidade, assumir o papel de formar profissionais conscientes de seu papel na sociedade; operadores do Direito qualificados para o exercício das diversas profissões jurídicas e conscientes do seu papel político dentro de uma sociedade em mudança.

Entretanto, como já referido, sabe-se que o atual ensino jurídico não promove substanciais alterações na sociedade, pelo menos não como deveria. Sabe-se da atual crise do ensino jurídico. Porém, o que não pode ocorrer é o conformismo com essa situação. Impõe-se uma profunda reformulação, uma verdadeira quebra de paradigma, pois não há espaço para a manutenção do ultrapassado sistema de ensino ainda vigente.

Leonel Severo Rocha e Bárbara Silva Costa referem expressamente que "falar sobre educação jurídica brasileira implica em assumir a existência de uma crise paradigmática no campo pedagógico". Aqui há apontamento do novo. Aqui há denúncia de que o velho não mais atende às necessidades e anseios da sociedade atual. Aqui há preocupação com o campo

\footnotetext{
${ }^{35}$ KENNEDY, Duncan. La enseñanza del derecho como forma de acción política. Buenos Aires: Siglo Veintiuno Editores, 2014. p. 24.

${ }^{36}$ RODRIGUES, Horácio Wanderlei. Pensando o ensino do direito no século XXI: diretrizes curriculares, projeto pedagógico e outras questões pertinentes. Florianópolis: Fundação Boiteux, 2005. p. 284.
} 
pedagógico, reconhecendo-se que o ensino jurídico deve focar em questões pedagógicas, justamente para alterar as práticas pedagógicas indesejáveis. Essas afirmações são corroboradas pela própria conclusão ${ }^{37}$ dos autores sobre o ensino jurídico ideal:

A partir de uma perspectiva waratiana busca-se a substituição do modelo de ensino tradicional adotado nas Faculdades de Direito por uma proposta pedagógica surrealista, capaz de promover a criatividade, a autonomia, a alteridade, a interdisciplinaridade e, acima de tudo, o amor.

O ensino jurídico precisa estar voltado para melhorar o mundo. Essa missão não pode ser ignorada. Logo, aos docentes do Direito é preciso buscar a meta, ainda que pareça utopia, de construir uma sociedade com cidadania plena a fim de consolidar uma sociedade mais justa e humana. ${ }^{38}$

Nas palavras de Antônio Alberto Machado, o ensino jurídico deve possuir a função de mudança social e, para tanto, precisa romper com o modelo didático-pedagógico tradicional (tecnicista e dogmático) que apenas mantém e reproduz as relações de poder vigente. Precisa o ensino jurídico "refazer seu papel na perspectiva de uma nova ordem social, como instrumento de justiça, numa sociedade reconhecidamente injusta". ${ }^{39}$

\section{CONCLUSÃO}

"A tirania, entre muitas outras vantagens, tem o privilégio de fazer e dizer o que lhe apraz". ${ }^{40}$ Trata-se de frase atribuída à Antígona, a qual costuma ser apontada como a fonte original da vertente do direito natural. Entretanto, a lição valiosa dessa importantíssima obra que se pode fazer em relação ao ensino jurídico está na sua concepção de contestação ao injusto, pois permite pensar e exercer um ensino jurídico muito diferente do que hoje vigora na maioria das faculdades do Brasil. Ainda temos um ensino jurídico estruturado para a educação e aplicação

\footnotetext{
37 ROCHA, Leonel Severo; COSTA, Bárbara Silva. Ensino do direito e percepções discentes: contribuições waratiana para a construção da pedagogia do novo. In: SILVEIRA; Vladimir Oliveira da; SANCHES, Samyra Haydêe Dal Farra Naspolini; COUTO, Mônica Bonetti (Orgs.). Educação jurídica. São Paulo: Saraiva, 2013. p. 292.

38 De acordo com PINTO, Daniella Basso Batista. Prática educativa do jurista em sala de aula: algumas considerações a respeito do pensamento de Charles Taylor e Paulo Freire. In: PINTO, Daniella Basso Batista; CINTRA, Rodrigo Suzuki (Orgs.). Direito e educação: reflexões críticas para uma perspectiva interdisciplinar. São Paulo: Saraiva, 2013, p. 41.

${ }^{39}$ MACHADO, Antônio Alberto. Ensino jurídico e mudança social. São Paulo: Atlas, 2012. p. 159.

${ }^{40}$ SÓFOCLES. Antígona. Tradução de Donaldo Scüller. Porto alegre: L\&PM, 1999. p. 39.
} 
das leis, baseado em antigos dogmas, servindo muito mais para manter a ordem já estabelecida do que propriamente para alterá-la.

A obra Antígona ainda é muito atual, pois ainda presenciamos muitas tiranias e injustiças num mundo tomado por desigualdades, em especial no Brasil. Nesse contexto, o ensino jurídico tem muito a contribuir, pois o mesmo precisa ser repensado para atingir a justiça social. Portanto, apenas através de uma mudança de paradigma é que o ensino jurídico adotará uma nova concepção voltada para a transformação social.

Para que isso de fato ocorra, precisa o ensino jurídico ter uma nova abordagem, ou seja, é essencial que sejam utilizadas práticas pedagógicas que conduzam o educando ao seguinte caminho: reflexão, crítica, emancipação e, por último, transformação social. Esse é o trilho que legitimamente deve se esperar dos futuros juristas, que precisam influenciar o mundo, atuar na sociedade, mas não para manter a desigualdade gritante já estabelecida, e sim para reduzir as injustiças e contribuir efetivamente para uma sociedade mais justa, harmoniosa e solidária. Não se defende o abando dos textos legais, mas sim um foco maior no contexto, no mundo que está ao redor do estudante de direito, que deve estar conectado com os problemas sociais.

Antígona morreu por defender o justo, por buscar a justiça apesar da tirania imposta. Ao ensino de direito cabe denunciar as injustiças, evidenciar as desigualdades, apontar os problemas existentes no universo jurídico e revelar as mazelas da sociedade, fomentando uma educação que leve à reflexão, à crítica e que gere no educando uma liberdade consciente a fim de buscar e criar soluções para que a justiça se efetive, o que gerará mudança social e, consequentemente, um mundo mais fraterno e solidário em que a justiça é o lema, a bandeira e o compromisso do ensino jurídico, sob pena deste não ter sentido, pois um ensino jurídico que não afronte a injustiça serve apenas para legitimar a tirania.

\section{REFERÊNCIAS BIBLIOGRÁFICAS}

ABIKAIR FILHO, Jorge. Democracia e educação para a cidadania, como uma forma de inclusão social. Revista de Direito Educacional, São Paulo, n. 5, p. 87-104, jan./jun. 2012.

ANDRADE, Cássio Cavalcante. Direito educacional: interpretação do direito educacional à educação. Belo Horizonte: Fórum, 2010.

BOAVENTURA, Bruno José Ricci. Antígona: a mãe da individualização do direito. Direito e Democracia: Revista de Ciências Jurídicas, Canoas, v.9, n.1, p. 120-129, jan./jun. 2008. 
CALHAU, Lélio Braga. O devido processo legal no processo penal: Da Antígona ao garantismo. O Direito em Movimento: Revista do Instituto Capixaba de Estudos. Vitória, v.1, p.125-142. 2000.

COSTA, Bárbara Silva. (Re)pensando o direito diante de um mundo global: uma reflexão sobre os desafios do ensino jurídico no século XXI. In: CERQUEIRA, Angélica Carlini; ALMEIDA FILHO, José Carlos de Araújo (Orgs). 180 anos de ensino jurídico no Brasil. Campinas: Millennium, 2007, p. 367-377.

FREIRE, Paulo. Pedagogia da autonomia: saberes necessários à prática educativa. São Paulo: Paz e Terra, 2011.

GERHARDT, Heinz-Peter. Educação libertadora e globalização. In: FREIRE, Ana Maria Araújo (Org.). A pedagogia da libertação em Paulo Freire. São Paulo: Editora UNESP, 2001, p. 101112.

GIANASI, Anna Luiza De Castro. A extensão na sala de aula: reflexões sobre a aplicabilidade de metodologia d problematização como instrumento de promoção da cidadania. In: XIMENES, Julia Maurmann; SILVA, Larissa Tefen (Orgs). Ensinar direito o Direito. São Paulo: Saraiva, 2015 .

GUIMARÃES, Cristiane Santana. Antígona, o exercício do direito natural. Revista da Procuradoria Geral do Estado da Bahia. Salvador, v. 31, p. 11-16, jul./dez., 2005.

KENNEDY, Duncan. La enseñanza del derecho como forma de acción política. Buenos Aires: Siglo Veintiuno Editores, 2014.

KRETSCHMANN, Ângela; OHLWEILER, Leonel Pires. Desencantamento do ensino jurídico: um paralelo com "O Admirável Mundo Novo", de Huxley. Revista Jurídica do Cesuca. v.4, n. 6, $\mathrm{jul} / 2014$.

LIMA, Francisco Gérson Marques de. O professor no direito brasileiro: orientações fundamentais de direito do trabalho. Rio de Janeiro: Forense, 2008.

LOPES, José Reinaldo de Lima. O direito na história: lições introdutórias. 5. ed. São Paulo: Atlas, 2014.

MACHADO, Antônio Alberto. Ensino jurídico e mudança social. São Paulo: Atlas, 2012.

MACIEL, Adhemar Ferreira. Um pouco de Antígona e de direito natural. Revista de Informação Legislativa, Brasília, n.132, p.37-38, 1996.

MAIA, T. Lisieux. Antígona: o trágico da ação e o aprendizado de si. Pensar: Revista do Curso de Direito da Universidade de Fortaleza, Fortaleza, v. 13, n. 1, p. 148-157, jan./jun. 2008.

MARQUES, Fabiano Lepre. Ensino jurídico: o embate entre a formação docente e o pacto de mediocridade. Revista de Direito Educacional, São Paulo, n. 3, p. 189-207, jan./jun. 2011. 
MARTÍNEZ, Sérgio Rodrigo. Pedagogia jurídica. Curitiba: Juruá, 2012.

MORAES, Alexandre de. Direitos humanos fundamentais. 3. ed. São Paulo: Atlas, 2000.

MOTA, Sergio Ricardo Ferreira. Metodologia do ensino crítico do Direito Tributário no Brasil: uma proposta para a superação da crise do ensino jurídico. Revista de Direito Educacional, São Paulo, n. 4, p. 337-360, jul./dez. 2011.

MUNIZ, Veyzon Campos. Superando Antígona. A distinção entre direito público e direito privado - Limites, enfraquecimento e consequências operacionais a partir de uma análise hermenêutica. Revista do Instituto de Hermenêutica Jurídica, Belo Horizonte , n.14, p.169-183, jul./dez. 2013.

OLIVEIRA, Juliana Ferreira de. Ensino jurídico: história que explica a prática docente. In: MIGUEL, Paula Castello; OLIVEIRA, Juliana Ferreira de (Orgs.). Ensino jurídico: experiências inovadoras. Rio de Janeiro: Lumen Juris, 2010.

OLIVEIRA, Rosa Maria R. de. Gênero, diversidade sexual e direitos humanos. In: RIFIOTIS, Theophilos; RODRIGUES, Tiago Hyra (Orgs.). Educação em direitos humanos: discursos críticos e temas contemporâneos. Florianópolis: Ed. da UFSC, 2008.

PAICENTIN, Antonio Isidoro. O direito à educação na Constituição Democrática de 1988. In: PINTO, Daniella Basso Batista; CINTRA, Rodrigo Suzuki (Orgs.). Direito e educação: reflexões críticas para uma perspectiva interdisciplinar. São Paulo: Saraiva, 2013.

PAULA, Giovani de. Alternativas pedagógicas para o ensino jurídico. In: COLAÇO, Thais Luzia (org.). Aprendendo a ensinar direito O DIREITO. Florianópolis: OAB/SC Editora, 2006, p. 212-237.

PINTO, Daniella Basso Batista. Prática educativa do jurista em sala de aula: algumas considerações a respeito do pensamento de Charles Taylor e Paulo Freire. In: PINTO, Daniella Basso Batista; CINTRA, Rodrigo Suzuki (Orgs.). Direito e educação: reflexões críticas para uma perspectiva interdisciplinar. São Paulo: Saraiva, 2013, p. 33-48.

PEDROSO, Regina Célia. Ciências sociais e direito: pensar o mundo a partir da reflexão crítica. In: PINTO, Daniella Basso Batista; CINTIA; Rodrigo Suzuki (Orgs). Direito e educação: reflexões críticas para uma perspectiva interdisciplinar. São Paulo: Saraiva, 2013.

RIBEIRO JÚNIOR, João. A formação pedagógica do professor de Direito: conteúdos e alternativas metodológicas para a qualidade do ensino do Direito. Campinas: Papirus, 2001.

ROCHA, Leonel Severo; COSTA, Bárbara Silva. Ensino do direito e percepções discentes: contribuições waratiana para a construção da pedagogia do novo. In: SILVEIRA; Vladimir Oliveira da; SANCHES, Samyra Haydêe Dal Farra Naspolini; COUTO, Mônica Bonetti (Orgs.). Educação jurídica. São Paulo: Saraiva, 2013. 
RODRIGUES, Horácio Wanderlei. Pensando o ensino do direito no século XXI: diretrizes curriculares, projeto pedagógico e outras questões pertinentes. Florianópolis: Fundação Boiteux, 2005.

SANCHES, Raquel Cristina Ferraroni; SOARES, Fernanda Heloisa Macedo. Construção da identidade docente do professor de direito. São Paulo: Letras Jurídicas, 2014.

SANTOS, André Leonardo Copetti; MORAIS, José Luis Bolzan de. O ensino jurídico e a formação do Bacharel em Direito: diretrizes político-pedagógicas do curso de Direito da UNISINOS. Porto Alegre: Livraria do Advogado, 2007.

SANTOS, Boaventura de Sousa. A universidade no século XXI: para uma reforma democrática e emancipatória da universidade. São Paulo: Cortez, 2004.

SCOZ, Alexandra Silva. Ensino jurídico de graduação brasileiro: ensaio sobre a produção de direito na pós-modernidade. Rio de Janeiro: Lumen Juris, 2012.

SIQUEIRA, Julio Pinheiro Faro Homem de. Ensino jurídico: em busca do habitus de transformação. Revista de Direito Educacional, São Paulo, n. 3, p. 217-260, jan./jun. 2011.

SÓFOCLES. Antígona. Tradução de Donaldo Scüller. Porto alegre: L\&PM, 1999.

\section{(Recebido em 18 de julgo e aprovado em 30 de agosto)}

